\title{
Hypertonic saline test for the investigation of posterior pituitary function
}

\author{
Angelika Mohn, Carlo L Acerini, Timothy D Cheetham, Stafford L Lightman, \\ David B Dunger
}

\begin{abstract}
The hypertonic saline test is a useful technique for distinguishing partial diabetes insipidus from psychogenic polydipsia, and for the diagnosis of complex disorders of osmoreceptor and posterior pituitary function. However, there is little information concerning its use in childhood. The experience of using this test in five children (11 months to 18 years) who presented diagnostic problems is reported. In two patients, in whom water deprivation tests were equivocal or impractical, an inappropriately low antidiuretic hormone (ADH) concentration ( $<1 \mathrm{pmol} / \mathrm{l})$ was demonstrated in the presence of an adequate osmotic stimulus (plasma osmolality > $295 \mathrm{mosmol} / \mathrm{kg}$ ). In two childrenone presenting with adipsic hypernatraemia and the other with hyponatraemia complicating desmopressin treatment of partial diabetes insipidusdefects of osmoreceptor function were identified. Confirming a diagnosis of idiopathic syndrome of inappropriate ADH secretion (SIADH) was possible in a patient with no other evidence of pituitary dysfunction. The hypertonic saline test was well tolerated, easy to perform, and diagnostic in all cases.

(Arch Dis Child 1998;79:431-434)
\end{abstract}

Keywords: hypertonic saline test; disorders of water balance; diabetes insipidus

Department of Paediatrics, John Radcliffe Hospital, Oxford, UK

A Mohn

C L Acerini

D B Dunger

Department of Paediatrics, Royal Victoria Infirmary,

Newcastle, UK

T D Cheetham

Department of Medicine, University of Bristol, Bristol, UK

S L Lightman

Correspondence to: Dr D B Dunger, Department of Paediatrics, Level 4, John Radcliffe Hospital, Oxford OX3 9DU, UK

email: david.dunger@,

paediatrics.ox.ac.uk

Accepted 22 April 1998
The differential diagnosis of polyuric states using standard diagnostic procedures such as the short and long water deprivation tests (WDT) are usually reliable in distinguishing severe central diabetes insipidus and nephrogenic diabetes insipidus from primary polydipsia. However, both central and nephrogenic diabetes insipidus may be partial, ${ }^{1}$ and polyuria associated with compulsive water drinking may limit the ability to concentrate urine. ${ }^{2}$ Diagnostic confusion between these conditions may arise as all are capable of producing a similar rise in urine osmolality using standard diagnostic procedures. ${ }^{3}$ Furthermore, complex disorders of osmoreceptor function such as essential hypernatraemia are rarely diagnosed using WDTs, as a hypovolaemic stimulus may result in apparently normal urinary concentrating ability. ${ }^{4}$

The hypertonic saline test offers an alternative approach to the diagnosis of polyuric states, as it defines the relation between plasma osmolality and plasma antidiuretic hormone
$(\mathrm{ADH})$ concentrations. The test is well established in adults ${ }^{5}$ yet there is little reported experience of its use in children.

We describe five cases in which the hypertonic saline test provided a clear diagnosis of various disorders of water balance where standard diagnostic procedures had failed or were deemed unreliable.

\section{Methods and materials}

All the tests were performed at the John Radcliffe Hospital, Oxford and informed consent was obtained from the patients and/or their parents. Before testing, each patient was assessed to exclude the presence of any confounding factor such as hypercalcaemia, hypokalaemia, glycosuria or any other cause of a solute diuresis. Free access to food and fluids, to maintain adequate hydration, was allowed until the morning of the tests.

WATER DEPRIVATION TEST

A seven hour water deprivation test was carried out between 08:30 and 15:30 using a standard procedure. ${ }^{7}$ The test was terminated before seven hours if urine osmolality concentrated to $>750 \mathrm{mosmol} / \mathrm{kg}$, if weight loss exceeded 5\% of initial body weight, or if the patient developed intolerable thirst.

DESMOPRESSIN TEST

An eight hour desmopressin test (DDAVP; Ferring, Middlesex, UK) was carried out between 08:00 and 16:00. The child was weighed and urine osmolality was measured before an intramuscular injection of desmopressin $(0.1 \mu \mathrm{g} / \mathrm{kg}$, maximum $4 \mu \mathrm{g})$. For the following hours the child was encouraged to void hourly. All urine was collected for measurement of urine osmolality.

\section{HYPERTONIC SALINE TEST}

Intravenous saline $(0.85 \mathrm{~mol} / \mathrm{l})$ was administered continuously $(0.05 \mathrm{ml} / \mathrm{kg} / \mathrm{min})$ through an indwelling catheter for up to a maximum of three hours, or until a plasma osmolality of $300 \mathrm{mosmol} / \mathrm{kg}$ was achieved. The patient remained supine from 30 minutes before and throughout the test. Blood samples were taken 30 minutes before and at 30 minute intervals from the start of the test into lithium heparin containers for measurement of plasma sodium, $\mathrm{ADH}$ concentrations, and osmolality. Urine samples were also collected before the start of the test and at 60 minute intervals, where possible, for measurement of urinary sodium and osmolality. Thirst behaviour and blood pressure were recorded at 30 minute intervals 


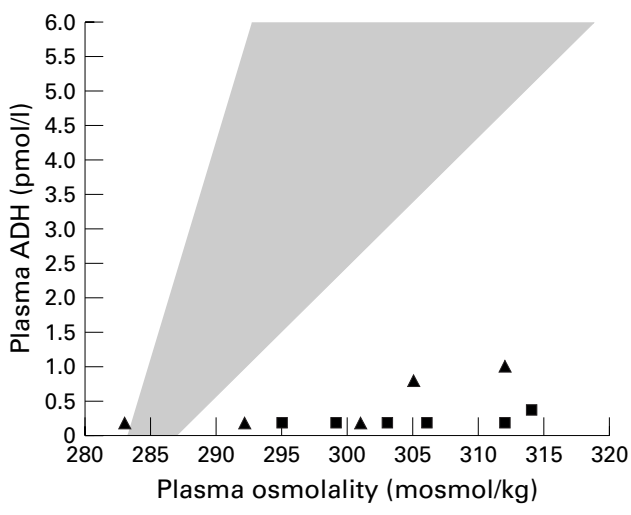

Figure 1 Plasma ADH related to plasma osmolality during hypertonic saline infusion in two patients (triangles, case 1; squares, case 2) with diabetes insipidus. The shaded area represents the normal range.

throughout. If the $\mathrm{ADH}$ response to a hypotonic stimulus was to be assessed the hypertonic challenge was preceded by an intravenous water load ( $20 \mathrm{ml} / \mathrm{kg}$ of $5 \%$ dextrose) given over two to three hours.

Plasma sodium and urine sodium were measured using standard laboratory methods. Urine and plasma osmolality were measured by freezing point depression (Microosmometre; Advanced Instruments, Vetech Scientific Ltd, West Sussex, UK). Blood for determination of plasma $\mathrm{ADH}$ was separated in a refrigerated centrifuge and stored at $-20^{\circ} \mathrm{C}$. Plasma $\mathrm{ADH}$ was measured by radioimmunoassay as previously described. ${ }^{8}$ The limit of detection of the immunoassay was $0.02 \mathrm{pg} / \mathrm{ml}$ (coefficient of variation intra-assay $9.7 \%$ and interassay $15.3 \%)$. All samples from each patient were measured in the same assay run.

\section{Case reports}

CASE 1

A 14 year old girl presented with a three month history of polydipsia (up to $14 \mathrm{1}$ /day) and polyuria. Significant emotional problems were identified. A frontal head injury with skull fracture had been sustained at the age of 13 years, and nine months before presentation a further minor head injury had occurred. All preliminary investigations were normal, except for a random prolactin concentration, which was raised to $2387 \mathrm{mU} / 1$. The WDT resulted in maximum urinary and plasma osmolalities of 287 and $289 \mathrm{mosmol} / \mathrm{kg}$, respectively. Responses to desmopressin were equivocal with baseline urinary osmolality $135 \mathrm{mosmol} / \mathrm{kg}$ reaching a maximum of $331 \mathrm{mosmol} / \mathrm{kg}$.

During the osmotic challenge with hypertonic saline (fig 1), a low maximal $\mathrm{ADH}$ $(1 \mathrm{pmol} / \mathrm{l})$ with raised plasma osmolality (312 mosmol/ $\mathrm{kg}$ ) was detected and established the diagnosis of partial diabetes insipidus. She is currently being treated with intranasal desmopressin (15 $\mu \mathrm{g}$ bid), thyroxine $(50 \mu \mathrm{g} /$ day), and hydrocortisone $\left(15 \mathrm{mg} / \mathrm{m}^{2} /\right.$ day $)$ as further evidence of anterior pituitary disease subsequently developed.

CASE 2

A 16 year old boy presented with extreme polydipsia (up to $121 /$ day) and other behav- ioural problems. He was diagnosed as having insulin dependent diabetes mellitus at the age of 8 years. His metabolic control had been poor over the previous year (mean HbA1c 11\%). At 15 years of age he developed a severe episode of diabetic ketoacidosis complicated by cerebral oedema and cerebral infarction, which had resulted in loss of short term memory.

Because of serious behavioural problems a WDT was impossible and a hypertonic saline test was performed. He had a small maximal increase of $\mathrm{ADH}(0.4 \mathrm{pmol} / \mathrm{l})$ during the test (fig 1), which was inappropriately low for the corresponding plasma osmolality (314 mosmol $/ \mathrm{kg}$ ). A diagnosis of diabetes insipidus was made and treatment with intranasal desmopressin $(10 \mu \mathrm{g}$ bid) was started.

CASE 3

This boy presented at 11 months old with an afebrile, generalised tonic clonic seizure. On admission, hyponatraemia (sodium $129 \mathrm{mmol} / \mathrm{l}$ ) was detected, which persisted despite fluid restriction. All preliminary investigations, including renal function, thyroid function (thyroid stimulating hormone $2 \mathrm{mU} / 1$, total thyroxine $123 \mathrm{nmol} / \mathrm{l}$ ), and adrenal function (random cortisol $426 \mathrm{nmol} / 1$, adrenocorticotrophic hormone $29 \mathrm{ng} / \mathrm{l}$, aldosterone 295 pmol/l) were normal. Random plasma osmolality and urine osmolality were $259 \mathrm{mosmol} / \mathrm{kg}$ and $955 \mathrm{mosmol} / \mathrm{kg}$, respectively, and plasma $\mathrm{ADH}$ was $2.98 \mathrm{pmol} / \mathrm{l}$. He had a low plasma osmolality (272 mosmol/ kg) at the beginning of the hypertonic saline test with inappropriately high plasma $\mathrm{ADH}$ (3.01 pmol/1) and an exaggerated $\mathrm{ADH}$ response (maximum $27.38 \mathrm{pmol} / \mathrm{l}$ ) during the osmotic challenge (fig 2). The syndrome of inappropriate $\mathrm{ADH}$ secretion (SIADH) was diagnosed and treatment with water restriction $(500 \mathrm{ml} /$ day) and demeclocycline $(150 \mathrm{mg}$ bid) was started. However, the hyponatraemia was corrected only after oral sodium supplements were added. Magnetic resonance imaging of the brain remained normal but secondary hypothyroidism developed and he is now receiving treatment with thyroxine $(50 \mu \mathrm{g} /$ day $)$.

CASE 4

A 4 year old boy presented with erratic drinking characterised by intermittent polydipsia (up to 5 1/day) and polyuria. Episodic headaches and aggressive behaviour had been noted. He had been diagnosed three years earlier with histiocytosis $\mathrm{X}$ with histologically confirmed lesions of the skin, ear, and lung, which had been treated with prednisolone. A WDT suggested partial central diabetes insipidus (maximum urine osmolality $630 \mathrm{mosmol} /$ $\mathrm{kg}$ ) and he was treated with intranasal desmopressin $(5 \mu \mathrm{g} /$ day $)$. However, on this treatment he developed progressive hyponatraemia and aggressive behaviour. A hypertonic saline test was performed (fig 3). At the beginning of the test $\mathrm{ADH}$ concentration was $0.74 \mathrm{pmol} / 1$ with a plasma osmolality of $288 \mathrm{mosmol} / \mathrm{kg}$. Subsequently $\mathrm{ADH}$ secretion was not suppressed following the water load $(0.95 \mathrm{pmol} / \mathrm{l})$ despite a decreasing plasma osmolality (283 mosmol/kg) 


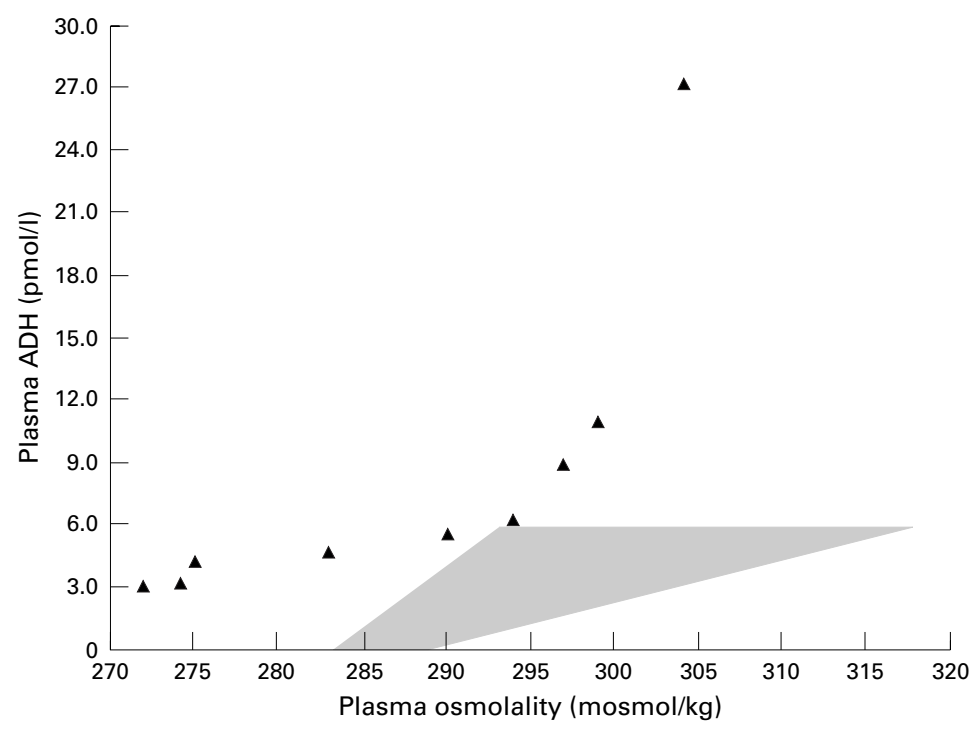

Figure 2 Plasma ADH related to plasma osmolality during hypertonic saline infusion in a patient with SIADH (case 3). The shaded area represents the normal range.

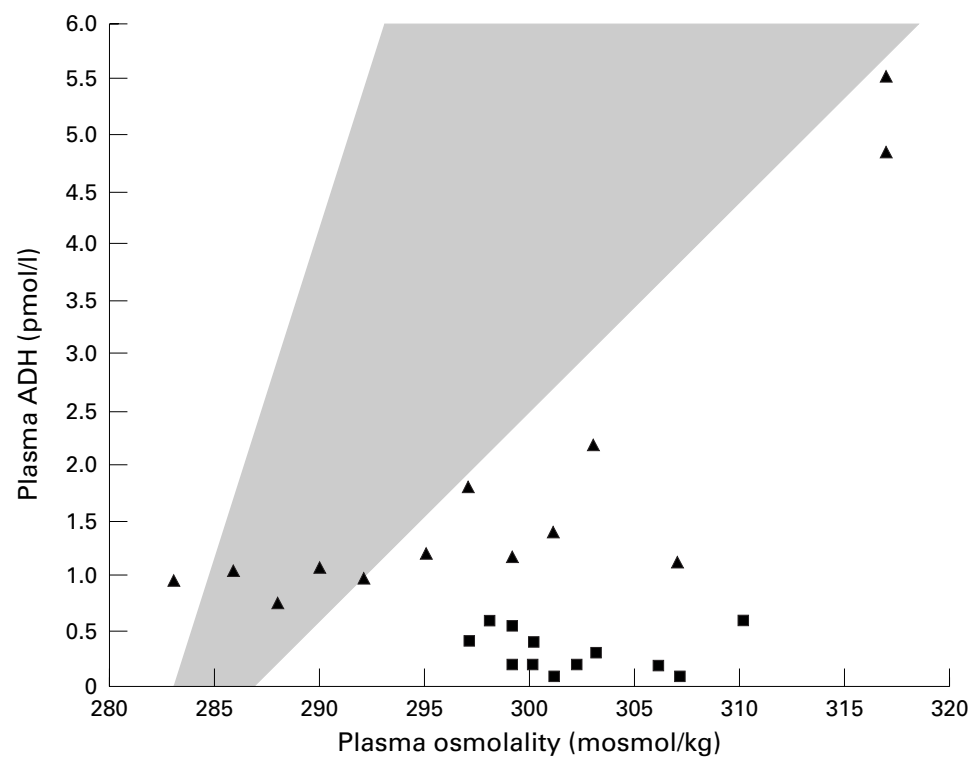

Figure 3 Plasma ADH related to plasma osmolality during water load and hypertonic saline infusion in one patient (case 4; triangles) with osmoreceptor defect and one (case 5; squares) with essential hypernatraemia associated with an osmoreceptor defect. The shaded area represents the normal range.

and was subnormally stimulated with osmotic challenge $(5.54 \mathrm{pmol} / 1$ at plasma osmolality of $317 \mathrm{mosmol} / \mathrm{kg}$ ). The diagnosis of osmoreceptor defect was established and his fluid balance is currently stable with desmopressin $(5 \mu \mathrm{g}$ once a week).

CASE 5

This boy was investigated at the age of 18 years because of adipsic hypernatraemia (sodium 147-153 mmol/1) and increased plasma osmolality (297-305 mosmol/kg). Polyuria was not evident and daily fluid intake varied between 1 and 1.5 litres. He experienced thirst only after heavy exercise. He also had abnormal aggressive behaviour and had precocious puberty and gynaecomastia.

After the water load, a hypertonic saline test (fig 3) was performed. Plasma $\mathrm{ADH}$ concentration before water loading was $0.6 \mathrm{pmol} / 1$ and plasma osmolality 310 mosmol $/ \mathrm{kg}$. By the end of the test the values were $0.2 \mathrm{pmol} / 1$ and $299 \mathrm{mosmol} / \mathrm{kg}$, respectively. During osmotic stimulation, no adequate $\mathrm{ADH}$ secretion could be detected (maximum $0.6 \mathrm{pmol} / \mathrm{l}$ ) despite increasing plasma osmolality (310 mosmol/ $\mathrm{kg}$ ) confirming the diagnosis of essential hypernatraemia associated with an osmoreceptor defect.

\section{Discussion}

An infusion of hypertonic saline with measurements of plasma osmolality and $\mathrm{ADH}$ is a simple and well tolerated means of assessing posterior pituitary function. It provides reliable information regarding the relation between plasma osmolality and $\mathrm{ADH}$. In normal adults and children there is a linear relation between those two parameters, which is described by a threshold and a slope. When the threshold (average $280 \mathrm{mosmol} / \mathrm{kg}$ ) is exceeded, $\mathrm{ADH}$ secretion rises sharply, which leads to antidiuresis and to increased urinary concentration. Below this threshold maximal urinary dilution occurs and $\mathrm{ADH}$ is undetectable with current radioimmunoassay methods. ${ }^{4}$ There is a wide interindividual variation in both the slope and threshold of the regression lines, but the relation is individually constant. ${ }^{9}$ Different pathological conditions alter this relation, and the hypertonic saline test can be used as a means of differentiating defects of water balance.

The standard WDT, relying on indirect assessment of $\mathrm{ADH}$ secretion, may not be sufficiently sensitive to identify patients with partial central diabetes insipidus from those with primary polydipsia. ${ }^{10}$ Incorporating plasma or urine $\mathrm{ADH}$ measurements to the test may be useful $^{1112}$; however, unless the plasma osmolality rises above the individual threshold for $\mathrm{ADH}$ release, a lack of $\mathrm{ADH}$ increase cannot be deemed pathological. In case 1 the WDT was not able to raise the plasma osmolality above $292 \mathrm{mosmol} / \mathrm{kg}$, the lowest level at which healthy subjects invariably have a rise in plasma ADH. ${ }^{9}$ Although different protocols for the WDT in children have been proposed ${ }^{12-14}$ it always involves a long period of observation. This needs careful monitoring of the patient, either because the child may drink while unattended or because potentially hazardous dehydration may occur. The hypertonic saline test is shorter, and with modern vein cannulation techniques well tolerated and easy to perform. The osmotic challenge given during the hypertonic saline test usually raises the plasma osmolality above the threshold of ADH release and permits diagnosis of partial diabetes insipidus as shown in our patients.

SIADH is a rare but well recognised disorder ${ }^{15}$ and the clinical diagnosis is based on features first proposed by Bartter and Schwartz in $1967 .{ }^{16}$ Once suspected, SIADH requires careful management with water restriction and sometimes by pharmacologically induced nephrogenic diabetes insipidus using demeclocycline. Patients with SIADH usually exhibit a characteristic response to water restriction: weight loss is accompanied by correction of hyponatraemia. The absence of such a re- 
sponse can make the diagnosis of SIADH doubtful ${ }^{17}$ and requires other means of confirmation. In our patient (case 3 ) the hypertonic saline test provided clear evidence of failure to suppress ADH completely when plasma osmolality fell below the threshold, followed by an exaggerated $\mathrm{ADH}$ secretion with respect to plasma osmolality during the osmotic challenge, diagnostic of SIADH. The hypertonic saline test provides a simple method for confirming persistence of SIADH at regular intervals as the natural outcome for idiopathic SIADH is unknown.

It is well known that histiocytosis $\mathrm{X}$ may present with disorders of water balance, such as partial central diabetes insipidus, because of infiltration of the posterior pituitary or hypothalamus resulting in local tissue damage. ${ }^{18}{ }^{19}$ However, more complex defects of water balance have also been reported. ${ }^{20}$ Although the WDT was indicative of partial central diabetes insipidus in case 4, treatment with modest doses of desmopressin was complicated by recurrent hyponatraemia. During the hypertonic saline test, preceded by a hypotonic stimulus, this patient showed a persistent secretion of small quantities of $\mathrm{ADH}$ when plasma osmolality fell below 284 mosmol/ $\mathrm{kg}$ and a subnormal ADH response when plasma osmolality increased. This indicates a selective defect of the osmostat characterised by relative insensitivity to either hypertonic or hypotonic influences. ${ }^{4}$ Patients with osmoreceptor dysfunction must be managed with particular care as they lack an effective defence against overhydration and underhydration. Free access to fluids or regular treatment with desmopressin can lead to water intoxication as shown by our patient, while lack of fluid intake may result in hypernatraemia. ${ }^{21}$ Stable water balance can be achieved using once weekly treatment with desmopressin. ${ }^{22}$

Essential hypernatraemia in association with defective osmoreceptor function, as shown by case 5 , can produce a difficult diagnostic problem that can only be resolved by the hypertonic saline test. ${ }^{23}$ Patients with selective osmoreceptor dysfunction may have normal ADH responses to hypotensive and other non-osmotic stimuli, but refractory responses to osmotic stimuli. ${ }^{24}$ This dissociation suggests normal haemodynamic control over ADH release. On the other hand, patients with partial central diabetes insipidus have a subnormal response of $\mathrm{ADH}$ not only to osmotic stimulation but also to non-osmotic stimulation. ${ }^{4}$ The dehydration achieved during the WDT may provide a hypovolaemic stimulus to the osmoregulatory system sufficient to stimulate $\mathrm{ADH}$ release. ${ }^{4}$ The diagnosis of selective osmoreceptor defects is therefore impossible to achieve with the standard WDT, but is easily characterised with the hypertonic saline test as this does not reduce blood volume.
Standard diagnostic tests for posterior pituitary disorders are usually reliable in most patients presenting with disordered water balance. Nevertheless, there are clear advantages to the direct osmotic stimulation of the posterior pituitary gland, and the hypertonic saline test may be used in situations where diagnostic difficulties arise.

We thank Miss Karen Jukes for performing the ADH assay.

1 Miller M, Dalakos T, Moses AM, Fellerman H, Streeten DHP. Recognition of partial defects in antidiuretic hormone secretion. Ann Intern Med 1970;73:721-9.

2 de Wardener HE, Herxheimer $\mathrm{H}$. The effect of high water intake on the kidney's ability to concentrate the urine in man. F Physiol 1957;139:45-52.

3 Robertson GL. Differential diagnosis of polyuria. Annu Rev Med 1988;39:425-42.

4 Baylis PH, Thompson CJ. Osmoregulation of vasopressin secretion and thirst in health and disease. Clin Endocrinol (Oxford) 1988;29:549-76.

5 Moses AM, Streeten DHP. Differentiation of polyuric states by measurement of responses to changes in plasma osmo-
lality induced by hypertonic saline infusion. $\mathrm{Am} \mathcal{F} \mathrm{Med}$ 1967;42:368-77.

6 Baylis PH, Robertson GL. Plasma vasopressin response to hypertonic saline infusion to assess posterior pituitary function. $7 R$ Soc Med 1980;73:255-60.

7 Dashe AM, Cramm RE, Crist CA, Habener JF, Solomon $\mathrm{DH}$. A water deprivation test for the differential diagnosis of polyuria. FAMA 1963;185:699-703.

8 Rooke P, Baylis PH. A new sensitive radioimmunoassay for plasma arginine vasopressin. F Immunoassay 1982;3:31330 .

9 Robertson GL. Physiology of ADH secretion. Kidney International 1987;32(suppl 1):S20-6.

10 Zerbe RL, Robertson GL. A comparison of plasma vasopressin measurements with a standard indirect test in the differential diagnosis of polyuria. $N \mathrm{Engl} f \mathrm{Med}$ the differential diagn

11 Milles JJ, Spruce B, Baylis PH. A comparison of diagnostic methods to differentiate diabetes insipidus from primary polyuria: a review of 21 patients. Acta Endocrinol Copenh 1983;104:410-16.

12 Dunger DB, Seckl JR, Grant DB, Yeoman L, Lightman SL. A short water deprivation test incorporating urinary arginine vasopressin estimations for the investigation of posterior pituitary function in children. Acta Endocrinol Copenh 1988;117:13-18.

13 Frasier SD, Kutnik LA, Schmidt RT, Smith FG. A water deprivation test for the diagnosis of diabetes insipidus for children. Am ₹ Dis Child 1967;114:157-60.

14 Richman RA, Post EM, Notman DD, Hochberg Z, Moses AM. Simplifying the diagnosis of diabetes insipidus in children. Am f Dis Child 1981;135:839-41.

15 Haycock GB. The syndrome of inappropriate secretion of antidiuretic hormone. Pediatr Nephrol 1995;9:375-81.

16 Bartter FC, Schwartz WB. The syndrome of inappropriate secretion of antidiuretic hormone. Am F Med 1967;42:790806.

17 Verbalis JG. Hyponatraemia. Baillieres Clin Endocrinol Metab 1989;3:313-30

18 Matus-Ridely M, Raney RB Jr, Thawerani H, Meadows AT. Histiocytosis X in children: patterns of disease and results of treatment. Med Pediatr Oncol 1983;11:99-105.

19 French Langerhans' Cell Histiocytosis Study Group. A multicentre retrospective survey of Langerhans' cell histiocytosis: 348 cases observed between 1983 and 1993 . Arch Dis Child 1996;75:17-24.

20 Dunger DB, Broadbent V, Yeoman E, et al. The frequency and natural history of diabetes insipidus in children with Langerhans-cell histiocytosis. N Engl f Med 1989;321: $1157-62$.

21 Robertson GL, Aycinena P, Zerbe RL. Neurogenic disorders of osmoregulation. Am f Med 1982;72:339-53.

22 Ball SG, Vaidja B, Baylis PH. Hypothalamic adipsic syndrome: diagnosis and management. Clin Endocrinol syndrome: diagnosis

23 Dunger DB, Lightman S, Williams M, Preece MA, Grant DB. Lack of thirst, osmoreceptor dysfunction, early puberty and abnormal behaviour in two boys. Clin Endocrinol (Oxf) 1985;22:469-78.

24 Halter JB, Goldberg AP, Robertson GL, Porte D. Selective osmoreceptor dysfunction in the syndrome of chronic hypernatremia. F Clin Endocrinol Metab 1977;44:609-16. 